\title{
Sharing Online Experiments - An Excellent Opportunity for Networking of Higher Education Institutions
}

\author{
https://doi.org/10.3991/ijim.v11i5.7068 \\ Radojka Krneta \\ University of Kragujevac, Cacak, Serbia \\ radojka.krneta@ftn.kg.ac.rs
}

\begin{abstract}
The opportunity for networking of higher education institutions (HEIs) by networking of their remote laboratories (RLs) is considered in this paper. Several important issues regarding successful HEIs networking by networking of their RLs are highlighted and resulted from a round table discussion during Experiment@ International Workshop 2016 “The Emerging Technologies on the Internet of Everything “-ETIoE'16.
\end{abstract}

Keywords - networking of higher education institutions, network of remote laboratories, sharing online resources

\section{Introduction}

In today's age of global knowledge and technology, networking and global awareness are increasingly viewed as major and sought-after assets. Internationalisation of a higher education institution (HEI) is a driver for change and improvement - it should help generate the skills of graduates required in the 21 st century. One of the main goals of internationalising HEIs is to provide the most relevant education to students, who will be the citizens, entrepreneurs and scientists of tomorrow [1]. HEI by its internationalisation may gain own a worldwide reputation, as well as a foothold in the international higher education community, and rise to meet the challenges associated with globalization. Additionally, internationalisation enables HEIs to increase national and international visibility, leverage institutional strengths through strategic partnerships, enlarge the academic community within which to benchmark their activities, mobilize internal intellectual resources, add important, contemporary learning outcomes to student experience and develop stronger research groups.

Today higher education is becoming more internationalised and increasingly involves intensive networking among HEIs, scientists, students and with other actors such as industry. Networking in higher education offers an excellent opportunity for promoting innovation and international collaborations, sharing experiences, highlighting the challenges, lessons learned, good practice and facilitation of cross-cultural and multidisciplinary dialogue. Thematic networks, like EIE- Surveyor [2] could enhance the attractiveness of the European Research Area, the links with industry, and participate in the continuous evolution of higher education in Europe. 
Information and Communication Technology (ICT) can be instrumental in better articulating the internationalisation process by networking and can actually contribute towards a qualitative change in it. ICT may offer new educational and research opportunities at a lower cost and with more flexibility, irrespective of physical location of HEIs. ICT enables virtual internationalisation, which can increase access and choice, as well as help mitigate brain drain, a critical concern for less developed countries [1].

Remote Laboratories (RLs) represent an excellent opportunity for one HEI to network and collaborate with other HEIs. By networking of their RLs, educational institutions will be able to afford better facilities for the education they provide, access the best lab facilities in other institutions, and substantially broaden the number of lab study items in their curriculum. RLs represent new opportunities for distance learning, in particular within the engineering and science disciplines, where hands-on experience is regarded as essential to acquire practical knowledge and skills.

One such important issue is integrating individual RLs on a network of RLs, which not only increases the pool of shared educational recourses and extends the laboratory base of individual HEIs by experiments aimed at related science fields, but also removes distance barriers and provides students and researches in one country with the opportunity to collaborate on laboratory experiments and projects with students and researches in other countries. The emerging importance of this attribute of network of RLs is seamlessly coupled with the emerging need for engineering graduates to be prepared to work within the modern collaborative international industrial environment [3].

RL networking is an integrated solution merging technical and pedagogical frameworks to support remote experimentation [4]. Technically, a RL network should be supported by an effective platform for RLs interconnection and sharing between different educational and scientific institutions. [5]. There are several known platforms for remote lab sharing like MIT iLab, ReLAX, LabShare, and WebLab-Deusto, or indexing systems as lab2go or Library of Labs (LiLa), but new ones continuously arise (NeReLa, GOLDi, Labicom, REMLABNET, iSES, LabsLand). Some chalenges and actions taken for interconnecting the NeReLa network with other EU networks of remote engineering labs are highlighted [6].

The NeReLa network has been established among the biggest four state universities in Serbia within the ongoing Tempus project NeRela [7]. Project partners agreed to share remote experiments from their laboratories as joint educational and research resources, enabling exchange of experiences regarding the introduction of innovative teaching methods in engineering education. One of the objectives of the NeReLa project is to include the formed network of remote engineering laboratories into the already established network of remote engineering laboratories in $\mathrm{EU}$, in order to spread European Engineering Community of Practice, as well to boost the internationalisation of Serbian universities.

Beside remote experiments, the internet of everything also includes online virtual experiments, online virtual and augmented reality experimentation and sensorial devices [8]. All these kinds of online experimentation open a wide spectrum of possibilities to improve the education quality level and could also be networked, making a network of online experiments. 
In order for a network of online experiments to be an excellent opportunity for networking of HEIs, the aims and objectives of RLs network have to meet networking mission statements defined by joint agreement of the involved HEIs. Those and other open questions concerning networking RLs as further online labs were discussed during a round table discussion at Experiment@ International Workshop 2016 "The Emerging Technologies on the Internet of Everything“" - ETIoE’16 [9].

\section{$2 \quad$ Sharing Online Experiments as an instrument for Networking of Higher Education Institutions - Important Issues}

During the round table discussion at Experiment@ International Workshop 2016 "The Emerging Technologies on the Internet of Everything" - ETIoE'16, several issues were considered regarding successful HEIs networking by networking of their RLs. Several aspects of RLs network establishment and its sustainable activity were highlighted.

\subsection{Joint projects as a way for funding RLs network establishment}

There are many examples of funding RLs network through joint projects of networked HEIs. During the project lifetime, providing funds for network establishment and work of qualified staff on hardware and software tasks is not a problem. But after the end of the project, the maintenance of RLs network and the provision of new highquality resources is left without a source of funding. For that reason, the willingness of HEIs to keep established networks active is crucial. Management of HEIs should be aware of the importance of using remote experimentation in innovative teaching and also of the contribution of RLs network for institutional development and the build up of institutional brand.

One good example of HEIs networking by networking of their RLs is the establishment of the NeReLa network within the ongoing Tempus project NeReLa. The rectors of the four biggest state universities in Serbia signed the agreement establishing the NeReLa network.

In terms of financial support, HEIs should also be aware of the complexity of RLs operation and therefore should be ready to set aside part of the funds for this purpose after the end of the project. In these terms the project should provide a sustainability strategy for attracting co-funding and other forms of project support for the beneficiaries $[10]$.

\subsection{Agreement among HEIs on RLs network establishment}

The aims and objectives of RLs network should meet HEIs networking mission statements such as exchanges between staff, student exchanges, joint graduate programs (with the use of RLs network resources), exchanging best practices and materials. 
The institutional management should be willing to support network establishment and activity. For that reason, before RLs network establishment, it is necessary to introduce the scope, aims and objectives of the network to institutional management, from the point of view of its contribution to institutional development. Moreover, the scope, aims and objectives of the network should be disseminated throughout each HE institution to be included in the RLs network.

Teaching staff of each networked institution should be well aware of what networks provide and be ready to use and adapt (if necessary) available network resources for their teaching purposes [1].

For ensuring the RLs network to be active after the end of project in which it has been established, an agreement among the networked HEIs has to be signed [7]. It will be convenient to provide the protocol with network resource maintenance as a part of the agreement of RLs network establishment.

\subsection{Building a joint platform of RLs network}

For a more comfortable and secure usage of RLs network resources, a joint platform for access to networked remote resources should be used. Designers of this platform should decide which kind of solution (purely software solution or softwarehardware solution) is more efficient for building the joint platform. They should have in mind who and how many will be users of network resources, and how often they will use the networked remote resources.

Besides solving hardware and software issues [5], other most important issues, such as the pedagogical approach to be adopted and the provision of resources and learning materials, will have to be solved in wide consultation with teachers who will use the remote resources for teaching purposes. All of them should keep in mind during the design of online experiments what are the differences and additional requirements in relation to the design of experiments in real laboratories [11], [12].

\subsection{Quality assurance of online resources}

For the purpose of quality assurance of online experiments and supporting learning materials, their assessment has to be performed continuously by different users (students, trained teachers) and external experts. The process of remote experimentation assessment is quite delicate having in mind the specific circumstances and mission of this kind of education.

Quality control of remote experiments and supporting learning materials within the Tempus project NeReLa have been performed through assessments by four target groups [13]:

- trained secondary vocational schools teachers;

- engineering students from Serbian partner universities who performed remote experiments within their lab exercises; 
- students from selected secondary vocational schools who performed lab exercises with remote experiments within their Exemplary classes under the guidance of their teachers;

- experts from EU partner universities.

The main goal of expert assessment was to find and report technical problems that might constitute an obstacle for the users, to point out good practices and to establish a set of general recommendations concerning the design, the implementation and the accompanying learning resources that a remote experiment should have in order to maximize its effectiveness as a tool to teach and to learn. An assessment instrument was developed and items were grouped in four factors (general technical aspects, quality of media feedback, documentation and help and quality of data collection). A report that includes an overall view of strengths, weaknesses, suggestions, comments and recommendations for the assessed online resources has been sent to the authors of these resources.

\subsection{Dissemination of RLs network}

For ensuring RLs network to be active and successful (of interest to a large number of users and experts), a wide variety of dissemination activities should be continuously performed.

The following activities are favorable for spreading network outputs and accessibility of its resources: joint publications, joint projects, conferences, workshops, promoting cooperation in the use of resources between different RLs networks, etc.

Most of the above mentioned dissemination activities have been realized within the NeReLa project with the aim of increasing the users of NeReLa resources and of including the NeReLa network into already established networks of remote engineering labs. There are several joint publications of the international NeReLa team ([6], [13], [14] and [15]) and they have become recognized actors in conference series like RE, exp.at, EDUCON, ICL and similar ones.

\section{Acknowledgment}

This work is a result of a round table discussion at Experiment@ International Workshop 2016 "The Emerging Technologies on the Internet of Everything " ETIoE'16 as well as a result of activities within the project 543667-TEMPUS-1-20131-RS-TEMPUS-JPHES "Building Network of Remote Labs for strengthening university-secondary vocational schools collaboration" supported by The Education, Audiovisual and Culture Executive Agency (EACEA). 


\section{$4 \quad$ References}

[1] F. Henard, L. Diamond, and R. Roseveare, "Approaches to Internationalisation and Their Implications for Strategic Management and Institutional Practice", A Guide for Higher Educational Institutions, OECD Higher Educational Programme IMHE, 2012.

[2] Maria João M. Martins, New Trends of Electrical and Information Engineering Higher Education in Europe, Thematic Network EIE-Surveyor REFERENCE POINT FOR ELECTRICAL AND INFORMATION ENGINEERING IN EUROPE, available on http://www.eie-surveyor.org/cd/index.htm

[3] A. Nafalski, Z. Nedic, J. Machotka, Ö. Göl, A. Scarino, J. Crichton, I. Gustavsson, J. M. Ferreira, D. Lowe and S. Murray, "International Collaboration in Remote Engineering Laboratories: an Approach to Development", IEEE TRANSACTIONS ON LEARNING TECHNOLOGIES, MANUSCRIPT ID, available on http://www.labshare.edu.au/media/ img/international collaboration remote labs.pdf

[4] J. M. Ferreira and D. Mueller, "The MARVEL EU project: A social constructivist approach to remote experimentation", Proceedings of the 1st Remote Engineering and Virtual Instrumentation International Symposium (REV 04), available on http://hdl.handle.net/10216/84634

[5] M. Kaluz, P. Orduna, J. G. Zubia, M. Fikar and L. Cirka, "Sharing Control Laboratories by Remote Laboratory Management System WebLab-Deusto", Preprints of the 10th IFAC Symposium Advances in Control Education The International Federation of Automatic Control August 28-30, 2013. University of Sheffield, Sheffield, UK, pp $345-350$. https://doi.org/10.3182/20130828-3-UK-2039.00074

[6] R. Krneta, A. Rojko, O. Dziabenko, T. Restivo, "NeReLa project: Building Network of Remote Labs using EU best practice", Proceedings on XI Congreso de Tecnología, Aprendizaje y Enseñanza de la Electrónica, Bilbao, del 11 al 13 de Junio del 2014, pp 355362 https://doi.org/10.1109/TAEE.2014.6900182

[7] Tempus project NeRela "Building Network of Remote Labs for strengthening universitysecondary vocational schools collaboration", available on http://nerela.kg.ac.rs/

[8] Xia Ping-Jun, António M. Lopes and Maria Teresa Restivo, "Virtual Reality and Haptics for Product Assembly, Surgical Simulation and Online Experimentation" Book chapter, Online Experimentation: Emerging Technologies and IoT, Editors: Maria Teresa Restivo, Alberto Cardoso and António Mendes Lopes, Publisher: International Frequency Sensor Association (IFSA) Publishing, pp. 315-330, ISBN: 978-84-608-5977-2, e-ISBN: 978-84608-6128-7, 30 December 2015.

[9] R. Krneta, "Sharing Online Experiments - An Excellent Opportunity for Networking of Higher Education Institutions", invited contribution, Experiment@ International Workshop 2016 "The Emerging Technologies on the Internet of Everything" - ETIoE, University of Azores, Ponta Delgada, Azores, Portugal, 5-6 Set, 2016.

[10] Kathleen Riggs, Strategies for Sustainability of Grant-funded Programs, Families and Communities, Utah State University Cooperative Extension, October 2012, available on http://extension.usu.edu/files/publications/publication/FC_Youth_2012-01pr.pdf

[11] Jing Ma and Jeffrey V. Nickerson, Hands-On, Simulated, and Remote Laboratories: A Comparative Literature Review, ACM Computing Surveys, Vol. 38, No. 3, Article 7, Publication date: September 2006, available on https://web.stevens.edu/jnickerson/ACM ComputingSurveys2006MaNickerson.pdf

[12] Dieter Muller, Heinz-H. Erbe, Collabortive Laboratories in engineering Education: Challenges and Vision, Chapter in the book of Luís Gomes, Javier Garcia Zubia "Advances on remote laboratories and e-learning experiences", Universidad de Deusto, 2008 
Special Focus Paper-Sharing Online Experiments - An Excellent Opportunity for Networking of High...

[13] R. Krneta, A. Rojko, M.T. Restivo, D. Urbano, "Evaluation of remote experiments by different target groups, NeReLa project case study", Proceedings on 13th International Conference on Remote Engineering and Virtual Instrumentation REV 2016, 24-26 February 2016, UNED, Madrid, Spain, pp 326-331

[14] The book "Online Experimentation: Emerging Technologies and IoT", Editors: Maria Teresa Restivo, Alberto Cardoso and António Mendes Lopes, Publisher: International Frequency Sensor Association (IFSA) Publishing, pp. 315-330, ISBN: 978-84-608-5977-2, eISBN: 978-84-608-6128-7, 30 December 2015

[15] Restivo, M. T., Krneta, R., Šešlija, D., Urbano, D., Zubia, J., “Discussion Table "Networking Online Experimentation", Proceedings of papers, International Conference on Electrical, Electronic and Computing Engineering, Zlatibor, Serbia, ISBN 978-86-7466-618-0, pp. AUI1.8.1-2, June $13-16,2016$.

\section{$5 \quad$ Author}

Radojka Krneta is with University of Kragujevac, Faculty of Technical Sciences Cacak, Cacak, Serbia (e-mail: radojka.krneta@ftn.kg.ac.rs).

Article submitted 27 April 2017. Published as resubmitted by the author 13 June 2017. 